\title{
BEING MUSLIM AND DOING ISLAM: NARRATIVES THAT INFLUENCE PHYSICAL ACTIVITY OF MUSLIM WOMEN IN NEW ZEALAND
}

\author{
Nargis Ali, Deborah Payne, \& Erica Hinckson
}

\begin{abstract}
Muslim women in New Zealand comprise ethnic and religious minorities. Research related to the physical activity levels of these women and their health status is sparse, particularly in the New Zealand context. International literature shows that Muslim women are at risk of various diseases related to inactivity. Islam, the religion followed by Muslims, is perceived by many Muslims as a way of life that influences almost all aspects of their lives. Particular understandings of Islam and women's roles within Islam influence the norms and expectations about health beliefs and physical activity. This study explored the role religion plays in shaping the physical activity of Muslim women in New Zealand. Findings revealed that the women related to Islam in different ways and practised the religion in ways which either facilitated or hindered physical activity. We identified two key constructs- 'being-Muslim' and 'Doing-Islam'-which helped us understand some of this variation in women's narratives about physical activity and Islam.
\end{abstract}

Keywords: Physical activity, Muslim women, culture

\section{INTRODUCTION}

The World Health Organisation (wHo) defines health as 'a state of complete physical, mental and social wellbeing and not merely the absence of disease or infirmity' (WHO 1985, 27). However, the meaning of health is not simple or singular because every culture espouses varied understandings of what constitutes health, wellbeing, sickness and disease, and practices various health behaviours to achieve optimum health (Davis and Dew 1999).

The physiological benefits of leading an active lifestyle (such as lowered risk of cardiovascular disease, obesity, heart disease, high blood pressure, osteo- 
porosis and diabetes mellitus) are well documented (see for example, Biddle and Mutrie 2001; Bouchard, Blair, and Haskell 2007; Dalziel, Segal and Elley 2007; Mosca, Benjamin, and Berra 2011). In addition, participation in sport and recreation offers a 'social and political space in which to cultivate cultural diversity and promote social inclusion' (Cortis, Sawrikar, and Muir 2007 1). However, the ability to participate itself is restricted for many social and cultural groups. Women's relationship with sport is seen by feminist writers as highly political and complex (Scraton and Flintoff 2002). For example, writers such as McKay (1991) consider sport as another institution, like education and employment, which seeks to reproduce patriarchal superiority. From a liberal feminist perspective women's participation in sporting activities is influenced by the socialisation of girls and women through family, media, school and society in general. In relation to the ability to engage in some forms of physical activity, women also have lower levels of financial independence compared to men (Bittman and Wajcman 2000, 166) and this restricts their activity levels.

Health promotion is a concept that has multiple meanings. One meaning has produced practices aimed at modifying lifestyles so the health risks for individuals or population groups are minimised. Examples of such health promotion campaigns in New Zealand include Push Play and 5+ A Day which have aimed at educating individuals regarding exercise and nutrition respectively. However, Cheek (2008) notes that health promotion is increasingly insistent that the duty of citizens is to maintain their health by adopting healthy lifestyles. Such health promotion strategies place the onus of health upon the individual, the assumption being that a healthy body and a healthy lifestyle are an individual's responsibility (Petersen and Lupton 1996, 64).

Crawford introduced the idea of 'healthism', the notion that capitalist cultures exert hegemonic power over understandings of health and health promotion. $\mathrm{He}$ argues that 'Like medicine, healthism situates the problem of health and disease at the level of the individual'. $(1980,366)$. Within such an ideology, the lack of health is attributed to individuals' 'moral laxity' (Dworkin and Wachs 2009 11). Healthism, for Crawford, is a manifestation of neoliberalism in which some groups of people are more privileged than others because of their ability to buy goods and services, which signify class and status, and through their cultural practices, which are legitimated as the right practices. Through practices of consumption (such as routinely attending the gym, undergoing cosmetic surgery etc.), these groups of people are able to cultivate the 'right' kind of body, an object of desire and a goal to be achieved. The right kind of body shape is a corporeal metaphor for health, and body shapes and sizes come to mean not just medico-scientifically 'good' but also morally 'good' ' (Crawford 
1980, 430). Disciplining the body becomes a project, a task of the morally responsible. Women are more likely to identify and conform with this task of controlling the body so that it fits the idealised size and structure. However, generalising the applicability of the healthism notion to Western or European women universally assumes a homogeneity among these women. In addition, it is important to realise that the literature pertaining to healthism has originated from English-speaking and European researchers. There may be many women who do not treat their bodies as a site of consumption and to whom key features of healthism do not apply.

In New Zealand, overweight/obesity and physical inactivity are one of the top six behaviours posing major health risks (Wilson et al. 2011). The relationship between health and physical activity and, conversely, the relationship between obesity and the lack of physical activity, occupy central importance in current debates regarding the wellbeing of New Zealand's populace (see for example Ministry of Health Report 2014 b,c). The minimum activity required by an individual on a weekly basis to qualify as an active person is 2.5 hours of moderate activity. This could include walking, running, cycling, unstructured activity and team sport. Less than this amount of activity classifies people as inactive (Dalziel, Segal, and Elley 2007, 57). According to Casperson, Powell, and Christenson $(1985,126)$, physical activity includes all movement but exercise is characterised by bodily movement resulting in high or low energy expenditure; it is planned and structured and is aimed at improving or maintaining physical fitness.

Here, physical activity is defined as intentional activity which is goal-directed in order to increase or maintain physical fitness. For the purpose of this study, we have not made the above distinction between physical activity and exercise but have included all activity done by a person as physical activity.

The annual health survey of New Zealand's adult population notes that approximately $46 \%$ of New Zealand's population is classed as inactive, and about $12 \%$ are active for less than 30 minutes a week (Ministry of Health 2014a). Migrant and minority groups have been identified as being more inactive than the mainstream population (Guerin, Elmi and Corrigan 2007; Shah and Culbertson 2011).

The Muslim population in New Zealand consists of various ethnicities; despite significant cultural variation among these ethnic groups, Islam provides a strong connection and basis for a religious identity. Islam spans various countries, societies and cultures, and the understanding of what Islam means also 
varies. Islam could mean the culture or traditions from a particular country or from a specific group of people who are Muslim, or Islam could refer to the practice of religious rituals or to spirituality. Culture may be understood as a group's 'specialized life-style consisting of their values, beliefs, artefacts, ways of behaving and ways of communicating' (DeVito 1992, 254). Muslim women's everyday practices are based on the religion of Islam and this behavior 'permeates their thinking patterns, their interaction with themselves and others, and all activities of their daily lives' (Carter and Rashidi 2004, 152). Islamic culture therefore 'refers to the lived experience of being a Muslim' (Dagkas and Benn $2006,23)$. Mawdudi $(1989,12)$ explains the notion of Islam as both religion and culture:

Islam is not a religion in the Western understanding of the word. It is at once a faith and a way of life, a religion and a social order, a doctrine and a code of conduct, a set of values and principles and a social movement to realize them in history.

International literature suggests that Muslim women might be more at risk of developing chronic diseases due to an inactive lifestyle (Dagkas and Benn 2006; Kahan 2003, 2009; Knop et al. 1996; Ludwig, Cox, and Ellahi 2011). For example, Muslim women who for religious beliefs wear veiling, are vulnerable to health risks including reduced calcium absorption, reduced bone density, hyperparathyroidism, increased risk of vertebral and hip fractures, myopathy and osteomalacia (Mason and Diamond 2001).

Studies in New Zealand and Australia about Muslim women demonstrate that the health problems this group of women experience transcend the country of their residence. Rather, the health issues seem to be an effect of their lifestyle which is in turn influenced by religious requirements. An Australian study conducted in 2001 identified severe cases of vitamin D deficiency among dark skinned women and Muslim women who were veiled (Mason and Diamond 2001). As vitamin $D$ in newborn babies is dependent on maternal transfer, these women's babies were also identified as below the reference range of vitamin D deficiency. Vitamin D deficiency and osteoporosis were also found in research conducted on Muslim women in Morocco (Allali et al. 2009). Muslim women in New Zealand, specifically Somali Muslim women, have been identified as a minority group who have low activity levels and a high rate of obesity (Guerin, Elmi, and Corrigan 2007), but the authors did not explore the reasons for inactivity. 
International research about Muslim women and exercise programmes is limited compared to research on the general population. Carroll, Ali, and Azam (2002) surveyed exercise on prescription (EoP) schemes in England and their effectiveness in increasing physical activity levels for South East Asian Muslim women. They estimated that since the 1990s there have been between $150-$ 200 such EoP schemes in England and Wales. Usually, they involved an initial health assessment by a general practitioner followed by a recommendation of physical activity such as swimming, aerobics, dancing or gymnastics. The study concluded that there was insufficient information about the effectiveness of such programmes for South East Asian Muslim women. The study did uncover barriers to exercise for this group of women such as: access to facilities, childcare options, perceived costs of participation, language barriers and cultural codes of conduct (Caroll et al. 2002). Similarly, Lawrence (2005) found that refugee women in Auckland, New Zealand, faced barriers to physical activity, such as resettlement issues, dealing with an unfamiliar healthcare system, difficulty in communication with providers, culturally acceptable exercise facilities, access to information, childcare and mental health issues. Somali Muslim refugee women had been successful in establishing a religiously acceptable exercise venue at a local swimming pool in Auckland, which was designed for Muslim women, but was open to women from other religious and cultural affiliations as well. At the time of the study, the swimming program had resulted in positive health outcomes for the Muslim women, such as reduced BMI, improved cardiovascular fitness, increased feeling of social cohesiveness and a sense of wellbeing.

Islam is regarded by its followers as a complete system of life (Kahan 2003), and therefore beliefs about health and illness cannot be understood separate from the religion. Some appreciation of the religious sentiment surrounding health and illness may contribute towards delivering health care which is suitable, and accessible, to Muslims living in New Zealand. The narratives of the Muslim women in this study may be regarded as a confluence of religious beliefs, gender role expectations and cultural practices. Therefore, this study aimed to explore the meaning of physical activity for Muslim women, and whether following the Islamic faith might affect the women's ability and willingness to engage in physical activity.

\section{METHODOLOGY AND METHODS}

The study uses postpositivism as its epistemological standpoint, and a qualitative descriptive approach as the methodology. Postpositivism has been proposed as one of the four paradigms used to group research methodologies 
(Grant and Giddings 2002). Researchers working in this paradigm assume that reality exists, but unlike positivists, regard reality to be contextual and therefore not generalisable, and only 'probabilistically apprehendable' (Carpiano and Daley 2006, 568). This position holds that 'true reality' can never be captured or accurately represented (Lincoln and Guba 2000). Using this approach allowed us to recognise the different meanings given to physical activity and their contextual nature. A qualitative descriptive methodology is congruent with the goal of describing or exploring a phenomenon. Sandelowski $(2000,335)$ suggests that qualitative descriptive studies are less interpretive than "interpretive description" in that they do not require researchers to move as far from or into their data'. Rather researchers 'stay closer to their data and to the surface of words and events' (336) than other qualitative researchers. In qualitative descriptive research, an event is described in everyday language without the 'interpretive spin' researchers from other qualitative methodologies might use (Sandelowski 2000, 336). A narrative makes the narrator's experience accessible to the listener, but of course a narrative is always something different from a "life-as-lived", that is, what actually happened - or from a "life-as-experienced" - that is, the images, feelings, desires, thoughts, and meanings known to the person whose life it is' (Sandelowski 1994, 26). Thus, this study emphasised the need to stay as close as possible to the narratives of the women who were interviewed, conveying the meanings intended by them, to the readers. The constructs of being-Muslim and doing-Islam were derived from the authors' understanding of the women's narratives. We acknowledge that the constructs are not fixed binaries; rather, that they form a fluid continuum for the women.

\section{Narrative as Method}

Narrative represents the experience of a woman and the perception of her role, identity and her part in the event she is narrating (Riessman 2012). It is a co-construction between the interviewer and interviewee. The way people see themselves is shaped by the culture that has conditioned them. Therefore, narrative is a cultural output. An event may be interpreted and narrated by two individuals in a completely different way. This is true even for people who belong to the same cultural, social or religious group, as their experiences will still be unique. Through the act of narrating, the narrator conveys not just past events, but the meaning associated with the experience, and the way the narrative came to be. Lieblich et al. $(1998,7)$ note that 'personal narratives, in both facets of content and form are people's identities'. Identities are constituted by multiple voices and sub-identities (Rowan and Cooper 1999), which the narrative researcher aims to access through the interview process. Narra- 
tives provide insight into the roles people play in their everyday lives and the identities they inhabit. This is especially important when conducting research with cultural groups because, as Dagkas and $\operatorname{Benn}(2006,23)$ note in their comparative study of Muslim women's participation in sport in Britain and Greece, 'Any research in this area needs to remain sensitive to the fact that individuals differentially negotiate their multiple and complex layers of identity'.

\section{Recruitment}

This research was carried out in a large city in New Zealand with a significant Muslim population. The advertisement for recruiting participants was placed in two central city mosques and at a community swimming pool which has women's only swimming and gym times. The advertisements were written in English, Urdu and Hindi to reach the greatest number of potential participants. These three languages were chosen as the primary researcher (NA), who conducted the interviews, is fluent in these and was able to also transcribe in Hindi and Urdu, and later able to translate the interviews into English.

The inclusion criteria for the study were that the women must: Identify as Muslim; be 20 years of age or more; exercise either not at all, up to 2.5 hours a week, or more than 2.5 hours a week (giving this range of physical activity ensured that the women who came forward for the interviews chose to class themselves as exercising extensively, moderately or not at all); and speak English, Urdu or Hindi. Of the twenty-nine women who responded to the advertisement, twenty-five met the criteria set out for the study. Of these women, seven belonged to a women's network at a mosque and wanted to participate in the study via a focus group. In discussion with the group's convenor, who was well-respected in the group and considered an elder, it became clear that some voices, especially those of the younger women in the group, would be silenced if their opinions differed from the others. This was due to the concept of respecting elders, important in a Muslim community, where younger members do not publicly disagree with the viewpoint of an older person, or do not openly discuss issues which they may consider inappropriate in front of an older person. Moreover, it was felt that the stories and the rich details of the women's lives could not be explored fully in a focus group. For these reasons the women were instead given an opportunity to participate in individual interviews. All seven declined this option. Finally, 16 interviews were conducted in total. Out of these, one participant rang the day following her interview and asked for it to be withdrawn from the study; no explanation was provided for this. 


\section{Data collection}

At the beginning of each interview the women were asked to explain what Islam meant to them, or the ways in which they related to Islam. This provided an open-ended, or exploratory, way to begin the interview and helped clarify each woman's relationship with the religion.

The style of the interview was casual, semi-structured and at a pace set by the women. As the interviews were premised on the power of narratives to co-construct meaning, the participants and the primary researcher, (NA), were interchangeably active listeners and speakers. NA identifies as a Muslim woman who has spent her early childhood in an Arab country and migrated to New Zealand as a teenager. She also wears the Muslim headdress on certain occasions such as formal religious gatherings, or when she was interviewing participants at the mosque.

Mishler describes the interview as 'A circular process through which [a question's] meaning and that of its answer are created in the discourse between interviewer and respondent as they try to make continuing sense of what they are saying to each other' $(1986,53-54)$. The women were asked to talk about: Islam and the level of physical activity they engaged in; the meaning of exercise; their experience with exercise and how it was regarded within their family and community, and if there were factors that hindered or facilitated exercise for them. Questions specifically relating to Islam's connection with health and exercise were not asked because we wanted the women to focus on Islam and physical activity so their narratives could yield rich insights into the relationships the women drew between them. Most of the women adopted a sequential style of storytelling, describing the way life events had happened, their impact on the way they followed Islam, and how they thought of physical activity. These reflected an almost chronologically ordered series of experiences, strung together by a kind of story plot. As Gubrium and Holstein suggest, interviews are recognized 'as a means of contemporary storytelling' $(1998,165)$. The interviews ranged in duration between 45-120 minutes. They were audio-recorded and transcribed verbatim. The two interviews which were conducted in Urdu and Hindi were translated and transcribed. The translated transcripts were then read back to the participants, and explained, to ensure that what they had intended had been accurately translated. The other transcripts were returned to the participants. Some women wrote comments on their transcripts to explain what they had meant. 


\section{Ethical Considerations}

The study was approved by the Auckland University of Technology's Ethics Committee (AUTEC). A Participant Information Sheet gave information about the study. Written informed consent was obtained from each participant before the interview commenced.

As recommended by AUTEC, advice was sought from a cultural advisor to ensure the cultural safety of the study participants. The advisor would: provide guidance in matters relating specifically to Islam, check that the cultural protocol being used in the study was appropriate, read the interview transcripts and have access to the interview recordings and be able to accompany the first author to interviews if required. Initially it was thought that the cultural advisor would be a woman. Finding a Muslim woman who had sufficient knowledge of Islam was difficult and made complicated by the very political and contestable space occupied by Muslim women both within Islam, and as an ethnic minority in New Zealand. After much searching, the only available and appropriate person was a Muslim man, who was an Islamic scholar and also had an interest in academia, with a post-graduate degree.

When the study was being designed, it was unclear whether a husband's consent was needed for married women to participate in the research. This uncertainty was based on the commonly held Islamic understanding that men are considered 'in charge of women' (The Quran, Chapter 4, Verse 34). Anecdotally, many Muslim women do ask for their husband's permission to participate in activities. However, the cultural advisor explained that this verse, understood in its context, means that men are in charge of providing financially for women and that women are considered equal, but different, to men. In Islam, women are not in a subservient position to men and, therefore, a woman does not need the consent of her husband to participate in any activity she chooses. As a result of this consultation, additional consent from husbands of participating women was not sought.

At the start of each interview, the information contained in the Participant Information Sheet, as well as their rights were explained. The participants' signed consent was gained after explaining the above details.

Two older women spoke in Urdu and Hindi, and the details of the study were explained to them in their language. However, as it transpired, they were more interested in finding out details about the primary researcher and her family, no doubt as a means of establishing rapport and trust. They seemed impa- 
tient with details about the research process, informed consent, or the benefits and risks associated with the study. We suggest this is because these women belonged to collectivist cultures. It is not uncommon for members of such cultures to rely on the context to draw the information needed. This is classed as 'high-context' communication. Geert Hofstede, an expert in cross-cultural issues, distinguishes between high- and low-context communications (Hofstede 2005). By gaining information about the researcher and more or less dismissing information about the study these women wanted to confirm whether the researcher belonged to the same culture as them, which would enable them to regard her as someone they could trust. Both the women remarked that as the researcher was a 'Muslim sister', they believed they could trust her and that they would sign the consent form.

As all the women belonged to a small and tightly-knit city Muslim community, confidentiality was especially important. All identifying information was changed and pseudonyms chosen by the women. Some women chose to use their given names as they considered it important that they retained ownership of their views and of their words. For example, one woman, who had established a sports association for Muslim women, expressed her expectation that readers of this study would identify and contact her to join the organization to increase its membership and to improve their physical activity. The consent forms, transcripts and recorded interviews were stored separately. As the cultural advisor would potentially have access to the transcripts, he was required to sign a confidentiality form.

\section{Analysis}

To become familiar with the different stories of the women, NA read and reread the transcripts, sometimes while listening to the taped interview. This helped to tease out significant factors affecting the participants' physical activity. Re-reading meant NA could identify emerging themes and 'metathemes'. A metatheme is more frequently drawn from the entire body of data or from a particularly powerful finding' (Clandinin 2007, 593). The metathemes identified were that Muslim women related to Islam in two distinct ways, which were termed for the purpose of this study: doing-Islam and being-Muslim. However, Belenki, Bond and Weinstock $(1997,119)$ caution researchers against attempting to categorize experiences by simplifying them. It was important to recognise that the labels, being-Muslim and doing-Islam, were constructs generated by the authors, and that not all the women fitted neatly into these throughout their narratives. 
As Bogdan and Biklen (1982) explain, interpretive data analysis means 'working with data, organizing it, breaking it into manageable units, synthesising it, searching for patterns, discovering what is important and what is to be learned, and deciding what you will tell others (145). Therefore, statements in the narratives which talked about aspects of being Muslim and the relationship between these and the particular notions of physical activity congruent with it were searched for.

\section{FINDINGS}

In total 15 women took part in the study. They ranged in age from 28 to 65 and identified as Indian $(n=3)$, Fiji Indian $(n=4)$, Iraqi $(n=1)$, Bangladeshi $(n=2)$, South African $(n=2)$, Zimbabwean European $(n=1)$, Malaysian $(n=1)$ and Samoan New Zealander $(n=1)$. All but one woman were immigrants who had migrated to New Zealand ranging from 35 to 5 years ago.

Of the 15 participants, eleven were married, two had never been married and two were divorced. Two women were 'reverts' or 'converts' to Islam. People who adopt the Islamic faith are referred to as reverts because it is believed that all humans are born as Muslim based on the Quran which states that before birth God makes humans testify that He is their creator (The Quran, Chapter 7, Verses 172-173).

Reading the narratives of the women in this study, it became evident that while all the participants identified as Muslim women, one group of women spoke about how their 'being' was Islam, how they could not identify a boundary between themselves and their religion. Being-Muslim is used as an extension of the adjective 'Muslim', showing the continuous state of 'being-ness' in which these women live.

The other group conceptualised Islam as a set of activities, rituals and prescribed behaviour. These we have identified as doing-Islam. By the term doing-Islam, we refer to those women who practise Islam as an activity or a set of rituals, the verb 'doing' illustrating the temporary nature of the activities undertaken. The following sections explain the distinction between the narratives of the being-Muslim and doing-Islam women and the implications for engaging in physical activity.

BEING MUSLIM AND IMPLICATIONS FOR PHYSICAL ACTIVITY

For the six being-Muslim women, presenting an identity congruent with their 
perception of Islam was important. Being-Muslim women's narratives showed that Islam was a central feature of their lived experiences. Their religion actively shaped decisions about work, play, exercise, marriage, child-rearing and care of the older family members. They could not conceive of themselves as separate from Islam. Being Muslim was their primary identity. To these women who followed Islam strictly, the religion is not simply one they follow during prayer times or at set occasions, such as during Ramadan, the month of fasting. Rather, they saw their religion as a way of life. As one of the women, Soraya explained:

I can't separate Islam from my life. Islam has always been who we are, who I am, it has been my guide through the most incredibly difficult journey I've had since coming to New Zealand ... [but] I believe it's a journey... God is the most incredible thing in my life, you got to do it [pray five times a day, wear hijab, do Ramadan] because it's right and the 'right' comes from God, because Islam gives us the right and wrong.

To be is to live as, incorporate and adhere to, Muslim principles. The 'being' becomes who the woman is. Women for whom 'being' Muslim is highly significant, placed greater emphasis on following religious rituals and practices. Their sense of right and wrong was derived from the religion and so were their resulting actions.

All of the being-Muslim women in this study wore a 'hijab' or head-scarf congruent with Islamic dress requirements for women. For some women, the external representation of religion was a positive reinforcer of religious identity and was not regarded as a barrier to exercise.

Soraya, spoke about finding the active and sporty culture of New Zealand a catalyst to increasing her activity levels. Soraya was also receptive to the idea of practising some poses and chants of yoga although these are regarded as anti-Islamic by many Muslim people. Soraya's conception of Islam as a positive force in her life helped her to overcome her inactive lifestyle and change her health and activity behaviour.

Soraya's narrative indicated that Muslim health beliefs are significant for women's engagement in sport. There are examples from Prophet Mohammed's life, known as hadees, which show that he valued physical fitness and advocated activities like swimming, archery, horse-riding and running. The second Caliph, Umar Ibn Khattab is reported to have said, 'Teach your children swimming 
and archery, and tell them to jump on the horse's back' (Qaradawy 1992, 296).

Another hadees tells the story of Ayesha, the Prophet's wife, who said that she raced with the Prophet and beat him in the race. Later, when she had put on some weight, they raced again, and he won. Then he said, 'this cancels that', referring to the previous occasion (Qaradawy 1992, 293). Ayesha is regarded as the source of authentic hadees in relation to Prophet Mohammed's life, and has narrated more hadees than anyone else (Barlas 2006, 145). This story narrated by Ayesha has reportedly set a precedent for some Muslim women to exercise, and specifically, to run (Walseth and Fasting 2003).

However, for the being-Muslim women who interpreted Islam more restrictively, the effect their religion had on physical activity was quite different. Jannah's story unfolded from the time of the tragic events of $9 / 11$ which drew her to explore Islam. Before this, she identified as a 'normal Kiwi woman', working fulltime. Reading the Quran and related commentaries convinced Jannah to accept Islam and since becoming Muslim her physical activity levels had declined sharply. Jannah's narrative shows that a change of religion may expose a person to a completely different way of life. Jannah had previously played touch rugby, soccer and netball competitively. Jannah recalled that from the time she accepted Islam her life changed dramatically:

and before I became a Muslim I used to be really sporty. I used to do marathons. and participated in a lot of sporting activities, and I was really quite....my weight was really quite well. I was about 69-68 kilos - I weigh just over 90 kilos now, but when I reverted to Islam of course I stopped doing sporting activities and of course I stopped running the roads because I started wearing hijab and it wasn't really appropriate for me to run in the streets with my hijab and with the abaya (a loose outer garment which is usually black, traditionally worn by Muslim women which completely covers their body).

After accepting Islam Jannah's identity changed. She adopted a lifestyle she believed was congruent with Islam. Becoming Muslim meant Jannah had to observe Islamic practices of specific behaviour and dress. The latter meant that her previous activities were no longer possible. Jannah realised that there was nothing within Islam that prohibited her from exercising in public, or at a mixed gender gym, as long as she was not exposing anything except her hands, feet and face. However, when walking or running outside, she found the abaya especially cumbersome because it would open up and flap in the wind', making her feel exposed and vulnerable even though she had normal 
clothing underneath.

Jannah had tried to maintain her physical activity when she first accepted Islam, but when she overtly identified as Muslim and either walked or ran outside, she often attracted racist, abusive and negative remarks from others:

I experience a lot of negativity from people when I am walking out on the streets, and, well, they just call me names, you know, like ninja... and of course it is not just when if I go walking on the streets, everywhere I go, if I do a bit of shopping... $\mathrm{f}$ course they don't know that I am Kiwi, because they can't see me underneath. They all think I am from a Middle Eastern country, or that I am Indian, because they call me Punjabi...I don't want to put myself in that situation. So I don't really go out on the roads anymore.

Jannah also considered joining a community gym but, as a mixed-gender gym, it and others were not suitable because Jannah believed that the form of the female body should not be exposed to men who are not mahram (either husband, father, brother, maternal and paternal uncles or nephews). Therefore exercising in such a setting would compromise her religious beliefs.

In addition, the music that generally accompanies aerobic classes in gyms was perceived by Jannah as a barrier to participating in this type of physical activity. Although there is no direct prohibition in the Quran against music, there are several hadees which prohibit the use of musical instruments by Muslims except the duff, which is a type of tambourine. Islam considers that music influences the mood and behaviour of a person and has a propensity to draw a person away from religion (Sahih Al-Bukhari, n.d.,volume 7, hadeeth 5590). Adhering strictly to an Islamic interpretation of permissible music, in this instance, poses an obvious barrier to Jannah's ability to exercise in gymnasia open to the public, or even in private women's gymnasia. It is understandable that Jannah lost her enthusiasm for sport and exercise under these circumstances.

An older being-Muslim woman, Saima, explained that the push to exercise and remain active despite one's age was a relatively new concept. She had migrated to New Zealand almost forty years ago. Prior to this, she was engaged in agriculture. In New Zealand she had worked at a factory. For her, physical activity had 'just happened' in the course of everyday living. However, her children who were all born in New Zealand insisted that she remain active by swimming and walking. Saima did not enjoy these activities because she believed 
that by praying five times a day as required by Islam, she was getting sufficient exercise and was fulfilling her religious obligations at the same time. The influence of pre-destiny, or the idea that a person's health, longevity, income and in fact all aspects of their worldly life, are pre-decided before they are born, was a strong theme in this narrative, illustrating that for some Muslims, pre-destiny rather than physical activity was believed to be responsible for positive health outcomes.

Another important factor for the physical activity of being-Muslim women is the role of the husband. In all narratives of the married Muslim women, the role of the husband in physical activity was pivotal. A husband's commitment to his wife's health and wellbeing appeared as a recurring theme in being-Muslim women's stories. One of the being-Muslim women in this study, Fatima, related that after migrating to New Zealand, she had faced a loss of social networks, isolation in a foreign country and did not have any familial support systems. Following the birth of her children her ability to exercise had reduced further. However her husband had helped her access a personal trainer who provided a home-based exercise regime which she had been following for a number of years.

Tasneem is the founder of an organisation, the Muslimah Sports Association, which aims to promote the uptake of physical activity among young Muslim women. The association provides religiously-suitable venues for activities like swimming, soccer, netball and basketball. Tasneem explained that in some families, the women are expected to be engaged in domestic activities, the care of the young and the aged as well as do all the cooking, leaving them little opportunity for organised sport. This problem is compounded by some women's belief that their husbands have the God-given right to decide what activities they will be involved in.

Many being-Muslim women experienced peer pressure to conform to the norms and behaviour of their in-group. M.A., a being-Muslim woman who wore full Islamic dress, talked about her experience of Muslim women becoming physically active, and the social pressure exerted upon them when they belonged to a sedentary group and tried to become active. M.A. referred to the cultural conditioning which resulted from the comments of Muslim women in her in-group, who criticised other women who attended the gym or who started to exercise. She felt that this negative criticism and gossip about women who were active acts as a deterrent to women who wished to exercise. She said this is because it was very important for women to 'fit in' with their circle of friends, more important than being physically fit. This view is reiter- 
ated by Dobson (2009), who explains that maintaining positive relationships within their community is important for Muslim women in New Zealand, because 'Muslim women in diasporic or minority populations may experience marginalisation and isolation....Faith and community tend to ameliorate the negative experiences for the women, as well as providing social networks and support' (ii-iii). Further, Dobson $(2012,108)$ observed in her research, that Muslim women in New Zealand articulated an identity that not only responds to stereotypical notions but also reflexively engages with wider negotiations between gendered 'cultural' notions and religious standpoints.

In light of the multiple and diverse viewpoints elucidated by the being-Muslim women, it may be said that traditional role expectations hinder some women's ability to engage in physical activity but families which prioritise exercise make it possible for women to become, and remain, physically active.

\section{DOING-ISLAM AND IMPLICATIONS FOR PHYSICAL ACTIVITY}

The 'doing' of Islam refers to specific acts of worship or rituals. Ten of the women who took part in this study perceived their practice of Islam as reflective of a balance between their religious identity and a secular New Zealand identity. Women in this study who are classified as doing-Islam follow the religion in discrete segments and do not identify primarily as Muslim, unlike being-Muslim women.

Well, obviously you know that my parents are Muslim and I was born into it so I would say the only practising thing I do, is not eat any pork. I have read the Quran when I was younger...but apart from that, that is about it. I probably follow some of the teachings but there are some things I do, which are not Islamic but that is about as much as I would [do]. But I mean because I was born in it I would still say I am Muslim by birth and follow some of the rules because that is how I have been brought up and apart from that, not very strict, not a very good Muslim (Farzana).

The narratives of doing-Islam women showed that they perceived their identity as a Muslim woman to be on par with their other identities, such as mother, daughter, worker and sportswoman. In comparison to the being-Muslim women, Islam was not an overarching factor which influenced all the other roles they inhabited. Neither was it considered a factor which mediated their activities related to work, leisure, or family life. These women's narratives showed a greater acceptance of the variability between, and among, Muslim women. The women allotted a specific time and space for religious activities, and the 
compartmentalisation of these activities allowed them to pursue a different, more secular, identity outside of the religion.

Drawing a direct and static relationship between doing-Islam and more physical activity, is problematic, because the constructs of 'being' and 'doing' tend to dichotomise the complex issue of religion and physical activity. However, all of the doing-Islam women were engaged in some form of physical activity at the time of interviewing. For example, two young women interviewed, Farzana and Tamsyn, did not present a public Muslim identity because they did not wear any article of dress which identified them as Muslim. Both of them remarked that they did not feel the need to publicly identify their faith, which was a personal thing for them. However, there are also several women who 'do Islam' but are wary of Western notions of physical activity and dress which they believe conflict with their perception of the correct way of following Islam.

Farzana had been playing soccer for several years in a mixed-gender team and considered Muslim dress restrictive for sport. She believed that strict followers of Islam would find it difficult to be physically active due to dress requirements and also because they could not play sport with men.

Some of the doing-Islam women described that adopting the Islamic dress was like a journey for them. The women who considered themselves moderately religious, Shabana and Nusrath, had felt that 'hijab was in the eyes', meaning that the way in which Muslim men and women interacted with each other as well as with non-Muslim men and women needs to be within prescribed Islamic guidelines, and does not need to be overtly represented in dress. For these women, mixed-gender sport was permissible in Islam as long as women played with the 'mahram' men of their families.

It was not only the being-Muslim women discussed earlier who felt that they could not exercise due to dress restrictions, but also some of the women who have been categorised as 'doing-Islam. Dr. Ahmed had worked as a medical specialist for several years overseas before immigrating to New Zealand, and dressed in European attire, but ensures her arms and legs are covered. She talked about her conditioning as a young Muslim woman, which still restricted the way she thought about the appropriateness or otherwise of certain types of exercise, like swimming. She was brought up in a conservative Muslim family and the fear of exposing the body in public meant she did not learn to swim or cycle. Even as an adult, she finds it difficult to swim in her private pool due to fear of accidentally exposing her body or its shape. Dr. Ahmed's story shows the entrenchment of the fear of exposing the body, even for some doing-Islam 
women, who do not appear to be as traditional as being-Muslim women. Her story represents the complex and intermingled nature of doing-Islam and being- Muslim, and shows that these categories are not fixed or easily demarcated.

Some doing-Islam women described the pressure exerted by their ethnic communities upon them, to conform to culturally acceptable standards of dress and behaviour. Farzana described how her mother has been told several times by members of their community to 'keep her in check' because she played soccer with boys, wore shorts for sport and stayed out playing until late. All these behaviours are not considered appropriate for a young Muslim woman, but are congruent with the identity Farzana had adopted, which is that of a fit, athletic young woman for whom work, health and sport were closely interwoven. Farzana has consciously distanced herself from her ethnic community, and has decided not to marry anyone who identifies as Muslim, especially from within her community, because she believes doing so would mean the end of her involvement in soccer. Similarly, Tamsyn believed that being involved in a Muslim group would negatively affect her ability to exercise because she thinks other women will try to judge whether she is being a 'good' Muslim woman based on her exercise routine. An in-group's ability to define and shape appropriate behaviour among its members can be significant (Griffin 1995, 404-406), and since Tamsyn was not part of a Muslim in-group she felt free from restrictive pressure to conform to sedentary behaviour. Both Tamsyn and Farzana were not affiliated with a Muslim or mosque-based socio-religious group, which may be a significant factor in their ability to pursue their sport without social pressure restricting them or questioning their activities. This was a crucial commonality among the doing-Islam women who were able to remain physically active away from religious and social criticism.

\section{DISCUSSION}

Analysis of the women's narratives showed that a Muslim woman's relationship with physical activity may be shaped by her relationship with Islam. For some being-Muslim women, especially the ones who adhere to a strict and/or patriarchal interpretation of Islam, the interpretation of Islam shapes participation in physical activity. Two metathemes, of being-Muslim and doing-Islam, were the main ways in which women related to the religion of Islam, and this relationship mediated their level of physical activity, and their beliefs about exercise.

Although all women identified as Muslim, the meanings they associated with living as Muslim women varied greatly. Gergen and Gergen (1987) note that 
narrations of experience depend on understanding of the self in relation to others and to the society, and that narrations are 'continuously unfolding stories in which plot and characters may change as situation and needs dictate' (124). The narrators' stories, in this study, showed the changing, and changeable, relationship of religion with their everyday activities. For some women, religion had been constantly significant or central to their belief system, while others showed varying and selective degrees of the acceptance of Islam. In both the being-Muslim and doing-Islam women's narratives, it was clear that the conceptualisation of Islam had an impact on involvement in physical activity. For some of the women Islam determined their everyday roles and activities. For other women, the religion was not so significant, and did not determine their everyday roles and activities. The narratives of the women emphasised their identities, whether Islamic (being-Muslim) or comparatively secular (doing-Islam). Similarly, Dagkas and Benn $(2006,23)$ note that 'Muslim females are not a homogenous group and that there are differences in the ways they choose to resolve religious and other cultural demands. Similalry, Kneza, Benn and Alkhaldic $(2014,1769)$ found that the women in their study who played football strove to maintain a balance between the Islamic dress code requirements and how they were expected to behave as women in public/ private spaces.

Most Muslim women who identified with New Zealand culture more than their ethnic culture were more inclined towards physical activity. These doingIslam women were more likely to have social and cultural affiliations outside of the religious circle, creating the spaces for them to be physically active with their non-Muslim peers.

The being-Muslim women were more inactive than the doing-Islam women. However, the being-Muslim women who did engage in physical activity consistently were the ones who had assimilated into New Zealand culture and also maintained their Islamic identity. They identified that their spouses' support enabled them to engage in physical activity.

It appeared that the way gender relations were conceptualised within the framework of Islam influenced whether women could exercise their choices regarding physical activity. It is important to differentiate between the Quranic rulings regarding the position of women vis-à-vis men, and the position of women as interpreted by men. This is not to satisfy an academic concern, but to legitimate the stand women can take with regard to male authority while not transgressing the Quran (unmediated by patriarchal interpretation). It may be that women have, under what we suggest is a misunderstanding, given 
the male figures in their lives (usually husbands) an inviolable and superior status, believing that status to be divinely sanctioned. Separating the blurred boundary between religion and socio-cultural practices may give women the ability to question and reconfigure the dynamics of gender relations within their families. Such a rethinking and renegotiation of the place a woman occupies in her family and in the public sphere is only possible when the inequality between gender roles is recognised as socially constructed, instead of divinely sanctioned. Zahraa $(2003,219)$ distinguishes between 'true Islam' and 'Muslim practices', and explains that practices which stem from Muslims' perception of Islam may be different to what Islam actually teaches. Zahraa also cautions researchers studying Muslim communities to be aware of the possible discrepancies between practised Islam and the intended meanings of Islamic law. Thus, what may seem as a valid justification for a husband to determine his wife's participation in physical activity, is not based on 'true Islam', but on a culturally constructed interpretation of Islam. Likewise, 'The problems of deciphering religious requirements from pseudo-religious community practices also add to the challenge of any research in this area' (Dagkas and Benn 2006, 23).

Islam and Muslims are regarded as a small but accepted part of New Zealand society despite global media popularising the notion of Muslims as terrorists (Dobson 2009; Pratt 2010). Pratt (2010, 402) observes that New Zealanders on the whole are accepting of Muslim women's dress codes, but it is the full facial coverings (niqab) which are 'regarded as vain and unnecessary, and often viewed by the wider public as in some sense threatening and implying an attitude of superiority on the part of the wearer. This corresponds with the findings in this study where one participant wearing a full facial veil was threatened while walking on the street, whereas participants who wore a head scarf (hijab), but no niqab, reported positive experiences while out walking or running in public. Muslim women's need to observe modesty and exercise away from a place where men could see them is also largely accommodated, for example the government's funding of a three-year partnership programme, Connect2Sport, to include youth from diverse ethnicities into sports like swimming, netball, badminton and football in Auckland. There is also a promising uptake of netball, swimming, football and badminton in the women-only organisation Muslimah Sports Association (partly funded by a local council), showing that Muslim women are willing to participate in sport and engage in physical activity.

LIMITATIONS OF THE STUDY

This study has provided an in-depth understanding of some aspects of the 
lives of Muslim women and their relation to physical activity. However, it has not provided information that could be used to understand other population groups' activity trends, such as those of non-Muslim migrants to New Zealand. Narratives of the participants in this study can by no means be considered representative of all Muslim women's experiences with regard to exercise.

As the sample size was 15, it is likely that there are other voices and differing experiences which are not included in the study. The inclusion criteria requiring that the participants be aged 20 years or more excluded younger women who may have had different experiences or emigrated to New Zealand as children, or been born in the country. Interviewing only women who could communicate in English, Urdu or Hindi meant that other Muslim women who do not speak these languages, such as Arab and African Muslim women, who also form a visible religious minority in New Zealand, could not be included in the study. Further, all the participants were recruited from one urban setting which has the largest population of Muslims in New Zealand. If participants had been recruited from other parts of New Zealand they may have contributed different perspectives to the findings.

\section{FUTURE DIRECTION}

It is important to realise the potential for future research based on the findings of this study. This study suggests that many Muslim women in New Zealand must transcend the parallel limitations of being immigrants to this country and also of finding spaces which allow them to remain sincere to their faith while being physically active. There is a need for a model to be developed which centralises the Muslim woman within the contexts which are meaningful for her, such as being a religious Muslim woman, being a wife or mother with domestic roles and responsibilities. It is possible to develop a person-centred model by which physical activity may be increased, and health outcomes enhanced while accommodating rules specific to Muslim women. This is because narratives in our study have shown that Muslim women are more involved in physical activity when their families, especially spouses, are supportive and when their interpretation of Islam is conducive to activity. Family-based decision making as well as the involvement of family in sport and physical activity are two important factors which affect the sustainability of an exercise programme for Muslim women. The Muslim community needs to be more aware of the significance of physical activity so that it can negotiate an appropriate level of activity for Muslims in New Zealand, and especially for Muslim women who are more sedentary than their male counterparts. Changes need to be made from within the Muslim community to include physical activity as an 
acceptable sphere of daily life, and the wider New Zealand community could make this possible by facilitating diverse opportunities for Muslim women to participate in physical activity.

\section{CONCLUSION}

This research sought to bring together the narratives of a cross-section of Muslim women in New Zealand about their physical activity. The main finding of this study was that Muslim women's participation in physical activity is mediated by their understanding and practice of Islam. In order to understand the way in which Islam is conceptualised, two constructs have been proposed: doing-Islam and being-Muslim. Women who do-Islam showed more involvement in different aspects of life in New Zealand. Most of them were younger women who had immigrated to New Zealand as children or adolescents. They reported that the majority of their social and support networks were derived from the friends they had made at school, university, or at work. These women were more physically active than the being-Muslim women. The women who do-Islam reported less restriction on their leisure activities due to their adoption of a more flexible, almost secular, interpretation of Islam. In addition this group had fewer familial responsibilities. Thus, in this study it was the manner in which the religion of Islam was conceptualised and practised, that either enabled or hindered the ability of Muslim women to engage in physical activity.

\section{REFERENCES}

Allali, F., Khazani, H., Benyahhia, B., Saoud, B., Kabbaj, S., Bahiri, R., Abouqal, R., and Hajjaj Hassouni, N. 2009. 'High Prevalence of Hypovitaminosis D in Morocco: Relationship to Lifestyle, Physical Performance, Bone Markers and Bone Mineral Density.' Arthritis and Rheumatology $38: 444-51$.

Barlas, A. 2006. 'Quranic Hermeneutics and Sexual Politics'. HeinOnline Cardozo Law Review 28:1431-52. Retrieved from: http://heinonline.org/HOL/ LandingPage?handle=hein.journals/cdozo28 \&div $=15 \&$ id

Belenki, M., Bond, L., and J.Weinstock. 1997. A Tradition That Has No Name. New York: Basic Books.

Biddle, S., and Mutrie, N. 2001. Psychology of Physical Activity. London: Routledge.

Bittman, M., and J. Wajcman. 200o. 'The Rush Hour: The Character of Leisure Time and Gender Equity'. Social Forces 79 (1):165-89. 
Bogdan, R., and Biklen, S. 1982. Qualitative Research for Education: An Introduction to Theory and Methods. Boston, MA: Allyn and Bacon.

Bouchard, C., Blair, S., and W. Haskell, eds. 2007. Physical Activity and Health. Champaign: Human Kinetics.

Carpiano, R., and Daley, D. 2006.'A Guide and Glossary on Post-Positivist Theory Building for Population Health'. Journal of Epidemiology and Community Health 6o (7):564-70.

Carroll, R., Ali, N., and Azam, N. 2002. 'Promoting Physical Activity in South Asian Muslim Women through Exercise On Prescription' Health Technology Assessment 6(8): 1.

Carter, D.J. and Rashidi, A. 2004. 'East Meets West: Integrating Psychotherapy Approaches for Muslim Women'. Holistic Nursing Practice 18 (3):152-59.

Caspersen, C., Powell, K., and Christenson, G. 1985. 'Physical Activity, Exercise, and Physical Fitness: Definitions and Distinctions for Health-Related Research'. Public Health Reports 100 (2):126-31.

Cheek, J. 2008. 'Healthism: A New Conservatism?' Qualitative Health Research 18 (7): 974-82. Retrieved from http://qhr.sagepub.com

Clandinin, D. 2007. Handbook of Narrative Inquiry. Thousand Oaks: Sage Publications.

Connect2Sport http://connect2sport.org.nz/

Cortis, N., Sawrikar, P., and Muir, K. 2007. Participation in Sport and Recreation by Culturally and Linguistically Diverse Women. University of New South Wales, Australia: Social Policy Research Centre.

Crawford, R. 1980. 'Healthism and the Medicalization of Everyday Life'. International Journal of Health Services 10:365-88.

Dagkas, S. and T. Benn. 2006. 'Young Muslim Women's Experiences of Islam and Physical Education in Greece and Britain: A Comparative Study'. Sport, Education and Society 11 (1):21-38.

Dalziel, K., Segal, L., and C. Elley. 2007. 'Cost Utility Analysis of Physical Activity 
Counseling in General Practice'. Australian and New Zealand Journal of Public Health 30 (1):57-63.

Davis, P., and K. Dew, eds. 1999. Health and Society in New Zealand. Auckland: Oxford University Press.

DeVito, J. 1992. The Interpersonal Communication Book. New York: Harper Collins Publishers.

Dobson, S. 2009. Faithful Living: Muslim women in New Zealand and the Articulation of Islam (Doctoral thesis). Dunedin: University of Otago.

Dobson, S. 2012. 'Contending With the Hyphen(S): Muslim Women Negotiating Identity, Gender and Conflict in New Zealand'. Sites: A Journal of Social Anthropology and Cultural Studies 9 (2): 92-113.

Dworkin, S., and F. Wachs. 2009. Body Panic. New York: New York University Press.

Gergen, K., and M. Gergen. 1987. 'The Self in Temporal Perspective'. In Life-span Perspectives and Social Psychology, edited by R. Ables, 121-37. Hillsdale: Lawrence Erlbaum.

Grant, B., and L. Giddings. 2002. 'Making sense of methodologies: A paradigm framework for the novice researcher'. Contemporary Nurse 13:10-28.

Griffin, E. 1995. A First Look at Communication Theory. New York: McGraw-Hill Inc.

Guba, E. 1990. 'The Alternative Paradigm Dialog'. In The Paradigm Dialog, edited by E.G. Guba, 17-30. Newbury Park: Sage.

Gubrium, J., and J. Holstein. 1998. 'Narrative Practice and the Coherence of Personal Stories'. Sociological Quarterly 39:163-87.

Guerin, P., Elmi, F., and C. Corrigan. 2007. 'Body Composition and Cardiorespiratory Fitness among Refugee Somali Women Living in New Zealand'. Journal of Immigrant and Minority Health 9:191-196. Retrieved from http://link. springer.com/article/10.1007/s10903-006-9030-X\#page-1

Hinchman, L., and S. Hinchman, eds. 1997. Memory, Identity, Community: The 
Idea of Narrative in the Human Sciences. New York: State University of New York.

Hofstede, G. and G. Hofstede. 2005. Cultures and Organizations: Software of the Mind. New York: McGraw Hill.

Kahan, D. 2009. 'Quantity, Type, and Correlates of Physical Activity among American Middle Eastern University Students'. Research Quarterly for Exercise and Sport $80(3): 412-24$.

Kahn, E., Ramsey, L., Brownson R., Health, G., Howze, E., Powell, K., Stone, E., Rajab, M., and P. Corso. 2002. 'The Effectiveness of Interventions to Increase Physical Activity'. American Journal of Preventive Medicine 22:73-107.

Kneza, K., Bennb, T., and S. Alkhaldic. 2014. 'World Cup Football as a Catalyst for Change: Exploring the Lives of Women in Qatar's First National Football Team - A Case Study'. International Journal of the History of Sport $31(14): 1755-73$.

Knop, P., Theeboom, M., Wittcock, H., and K. de Martelear. 1996. 'Implications of Islam on Muslim Girls' Sport Participation in Western Europe'. Sport, Education and Society 1 (2):147-64.

Lawrence, J., and R. Kearns. 2005. 'Exploring the 'Fit' Between People and Providers: Refugee Health Needs and Health Care Services in Mt Roskill, Auckland, New Zealand'. Health and Social Care in the Community 13 (5):451-61.

Lieblich, A., Tuval-Mashiach,R., and T. Zilber. 1998. Narrative Research: Reading, Analysis and Interpretation. London: Sage.

Lincoln, Y., and E. Guba. 200o. 'Paradigmatic controversies, contradictions, and emerging confluences'. In Handbook of qualitative research, edited by $\mathrm{N}$. Denzin and Y. Lincoln, 163-88. Thousand Oaks: Sage.

Ludwig, A., Cox, P., and B. Ellahi. 2011. 'Social and Cultural Construction of Obesity Among Pakistani Muslim Women in North West England'. Public Health Nutrition 14 (10):1842-50.

McKay, J. 1991. No Pain No Gain? New Jersey: Prentice Hall.

Mason, R., and T. Diamond. 2001. 'Vitamin D Deficiency and Multicultural Aus- 
tralia. Medical Journal of Australia 175 (5):236-37.

Mawdudi, A. 1989. Towards Understanding Islam. Leicester: Islamic Foundation.

Ministry of Health. 2014a. Actions to Encourage Healthy Weight and Healthy Lifestyles. Wellington: Ministry of Health.

Ministry of Health. 2014b. Annual Update of Key Results 2013/14: New Zealand Health Survey. Wellington: Ministry of Health.

Ministry of Health 2014c. The Health of New Zealand Adults 2013/14: Key findings of the New Zealand Health Survey. Wellington: Ministry of Health.

Mishler, E. 1986. Research Interviewing: Context and Narrative. Cambridge: Harvard University Press.

Mosca, L., Benjamin, E., and K. Berra. 2011. 'Effectiveness-based guidelines for the Prevention of Cardiovascular Disease in Women:2011 update: A guideline from the American Heart Association'. Circulation 123:1243-62.

Peterson, A., and D. Lupton. 1996. The New Public Health: Health and Self in the Age of Risk. St. Leonards: Allen and Unwin.

Pratt, D. 2010.'Antipodean Angst: Encountering Islam in New Zealand'. Islam and Christian-Muslim Relations 21 (4):397-407. Retrieved from http://dx.doi.org /10.1080/09596410.2010.527107

Qaradawy, Y. 1992. The Status of Women in Islam. Cairo: Islamic Home Publishing and Distribution.

Riessman, C. 2012. 'Analysis of Personal Narratives'. In Handbook of Interview Research, 2nd edn, edited by Gubrium, J., and J. Holstein, 367-81. London: Sage.

Rowan, J., and M. Cooper, eds. 1999. The Plural Self. London: Sage.

Sahih Al-Bukhari narrated by Abu Huraira. Retrieved January 7, 2012 from http:// www.searchtruth.com

Sandelowski, M. 1994. 'We Are the Stories We Tell: Narrative Knowing in Nursing Practice. Journal of Holistic Nursing 12 (1):23-33. 
Sandelowski, M. 200o. 'Whatever Happened to Qualitative Description?'. Research in Nursing \& Health 23:334-40.

Scraton, S., and A. Flintoff, eds. 2002. Gender and Sport: A Reader. New York: Routledge.

Shah, K., and P. Culbertson. 2011. 'Mental Health Awareness among Imams Serving New Zealand's Muslim Population'. New Zealand Journal of Counseling 31(1):87-97.

The Quran. Saheeh International. 2009. The Quran-English Meanings, revised and edited by Saheeh International. Riyadh: Al-Muntada Al-Islami Trust.

Walseth, K., and K. Fasting. 2003. 'Islam's View on Physical Activity and Sport: Egyptian Women Interpreting Islam'. International Review for the Sociology of Sport 38. Retrieved from http://irs.sagepub.com?content/38/1/45

wH0.1985. Targets for Health for All. Copenhagen: Denmark

Wilson, N., Blakely, T., Foster, R., Hadorn, D., and T. Vos. 2011. 'Selecting Priority Health Risk Factors for Researching Preventive Interventions: A New Zealand Example'. Poster Abstract. Journal of Epidemiological Community Health 65. Retrieved from http://jech.bmj.com.ezproxy.aut.ac.nz/content/65/ Suppl_1/A314.2

Zahraa, M. 2003. 'Unique Islamic Law Methodology and the Validity of Modern Legal and Social Science Research Methods for Islamic Research'. Arab Law Quarterly 18 (3):215-249. Retrieved from: http://scholar.google.co.nz/schola $\mathrm{r}$ ?hl=en\&q=Zahraa\%2C+M.+2003.\%E2\%80\%99Unique+Islamic+Law+Me thodology $+\& b \operatorname{tnG}=\& a s \_s d t=1 \% 2 C_{5} \& a s \_s d t p=$ 